\title{
The Three Lineages of the Diploid Hybrid Verticillium longisporum Differ in Virulence and Pathogenicity
}

\author{
Fluturë Novakazi, Patrik Inderbitzin, German Sandoya, Ryan J. Hayes, Andreas von Tiedemann, and Krishna V. Subbarao \\ First and fifth authors: Plant Pathology and Crop Protection Division, Department of Crop Sciences, Faculty of Agriculture, Georg-August \\ University of Göttingen, Grisebachstraße 6, D-37077 Göttingen, Germany; second and seventh authors: Department of Plant Pathology, and \\ third author: Genome Center and Department of Plant Sciences, University of California, Davis; and fourth author: United States Department \\ of Agriculture-Agricultural Research Service, 1636 E. Alisal Street, Salinas, CA 93905.
}

Accepted for publication 9 January 2015.

\begin{abstract}
Novakazi, F., Inderbitzin, P., Sandoya, G., Hayes, R. J., von Tiedemann, A., and Subbarao, K. V. 2015. The three lineages of the diploid hybrid Verticillium longisporum differ in virulence and pathogenicity. Phytopathology 105:662-673.

Verticillium longisporum is an economically important vascular pathogen of Brassicaceae crops in different parts of the world. V. longisporum is a diploid hybrid that consists of three different lineages, each of which originated from a separate hybridization event between two different sets of parental species. We used 20 isolates representing the three $V$. longisporum lineages and the relative $V$. dahliae, and performed pathogenicity tests on 11 different hosts,

including artichoke, cabbage, cauliflower, cotton, eggplant, horseradish, lettuce, linseed, oilseed rape (canola), tomato, and watermelon. $V$. longisporum was overall more virulent on the Brassicaceae crops than $V$. dahliae, which was more virulent than $V$. longisporum across the nonBrassicaceae crops. There were differences in virulence between the three V. longisporum lineages. V. longisporum lineage A1/D1 was the most virulent lineage on oilseed rape, and $V$. longisporum lineage A1/D2 was the most virulent lineage on cabbage and horseradish. We also found that on the nonBrassicaceae hosts eggplant, tomato, lettuce, and watermelon, V. longisporum was more or equally virulent than $V$. dahliae. This suggests that $V$. longisporum may have a wider potential host range than currently appreciated.
\end{abstract}

Verticillium longisporum is a fungal plant pathogen that infects the vasculature (9) of Brassicaceae crops (16). One of the most severely affected hosts is oilseed rape (canola) in Europe, specifically France, Germany, Russia, and Sweden (14), where disease incidence of up to $80 \%$ (7) and yield losses of up to $50 \%$ (8) were reported. Other hosts include broccoli in Italy; cabbage in Japan and the United States (California); cauliflower in Belgium, Germany, Netherlands, and the United States (California); field mustard in Italy, Japan, and Sweden; horseradish in Japan and the United States (Illinois); and radish and turnip in Japan (14). Sugar beet in Sweden is the only non-Brassicaceae host from which $V$. longisporum has been isolated (14). V. dahliae, a close relative $(14,15)$, causes Verticillium wilt (11) on a variety of different crops (16). Similar symptoms can result from infection by $V$. longisporum (27) but, in oilseed rape, $V$. longisporum induces premature ripening and early senescence (25), while wilting symptoms are absent (10).

Once established, $V$. dahliae and $V$. longisporum are difficult to eradicate (23). Verticillium spp. are soilborne and form microsclerotia, which are clusters of melanized cells that survive in the absence of a host for at least 14 years (30). In the proximity of a host root and in response to root exudates, microsclerotia germinate, and the hyphae penetrate and colonize the root vasculature, where they spread and proliferate into the plant vessels.

V. longisporum has an unusual evolutionary history. It is a diploid hybrid that evolved at least three different times, by hybridization between four ancestral lineages representing three different species

Corresponding author: K. V. Subbarao; E-mail address: kvsubbarao@ucdavis.edu

*The $e$-Xtra logo stands for "electronic extra" and indicates that five supplementary tables are published online.

http://dx.doi.org/10.1094/PHYTO-10-14-0265-R

This article is in the public domain and not copyrightable. It may be freely reprinted with customary crediting of the source. The American Phytopathological Society, 2015.
(15). The ancestral lineages include the unknown, hypothetical Species A1 and Species D1, the V. dahliae lineage D2, and the V. dahliae lineage D3. Species A1 hybridized with Species D1, $V$. dahliae lineage $\mathrm{D} 2$, and $V$. dahliae lineage $\mathrm{D} 3$, resulting in the V. longisporum lineages A1/D1, A1/D2, and A1/D3, respectively.

Hybridization is known to generate new plant pathogens (3), including $V$. longisporum, which is more virulent on oilseed rape than $V$. dahliae (9). Due to the involvement of different ancestors and potential lineage-specific genetic and epigenetic changes following hybridization (22), differences in pathogenicity and virulence may also exist between $V$. longisporum lineages. This is supported by the fact that, among $V$. longisporum lineage A1/D1 and A1/D3 isolates included in pathogenicity tests on cauliflower and oilseed rape, the $V$. longisporum lineage A1/D3 isolates were the least virulent group $(15,32,33)$. However, only two $V$. longisporum lineage A1/D3 isolates were used, and lineage A1/D2 isolates were missing in these studies.

Therefore, the objectives of this study were to test whether the three $V$. longisporum lineages differ with respect to pathogenicity and virulence. We performed greenhouse pathogenicity assays with $20 \mathrm{~V}$. longisporum and V. dahliae isolates on 11 different hosts, which included Brassicaceae hosts and other important crops.

\section{MATERIALS AND METHODS}

Pathogenicity and virulence of $20 \mathrm{~V}$. dahliae and $\mathrm{V}$. longisporum isolates were determined on 11 hosts. Artichoke, lettuce (Asteraceae), cotton (Malvaceae), eggplant, tomato (Solanaceae), and watermelon (Cucurbitaceae) experiments were performed at the University of California (UC) Davis and cabbage, cauliflower, horseradish, oilseed rape (Brassicaceae), and linseed (Linaceae) experiments at the University of Göttingen, Germany.

Fungal strains and inoculum production. Information about the 20 fungal isolates used in the experiments including host and geographic origin is provided in Table 1. Isolates were 
previously identified based on DNA sequencing and phylogenetic analyses as $V$. longisporum lineages A1/D1, A1/D2, or A1/D3 and $V$. dahliae lineage $\mathrm{D} 2$ or $V$. dahliae main group by Inderbitzin et al. (15), and Tran et al. (28) for strain PD639 (=V143).

To inoculate artichoke, cotton, eggplant, lettuce, tomato, and watermelon, all isolates were grown in 10-cm Petri plates on potato dextrose agar medium (PDA) (Sigma-Aldrich, St. Louis) at room temperature $\left(24 \pm 2{ }^{\circ} \mathrm{C}\right)$ in the dark for approximately 6 weeks. Conidia stock suspensions were prepared by pouring sterile distilled water into plates and dislodging conidia with a sterile pipette tip. Stock volumes and concentrations were $50 \mathrm{ml}$ and $>20 \times 10^{6}$ conidia $\mathrm{ml}^{-1}$, respectively, as determined by using a hemocytometer. Stocks were prepared the day before inoculation and stored at $4{ }^{\circ} \mathrm{C}$ overnight.

To inoculate cabbage, cauliflower, horseradish, linseed, and oilseed rape, isolates were grown on PDA (Carl Roth $\mathrm{GmbH}+\mathrm{Co}$ $\mathrm{KG}$, Karlsruhe) in Petri dishes for 10 days at room temperature. Two to three agar discs ( $5 \mathrm{~mm}$ in diameter) were transferred into $500-\mathrm{ml}$ Erlenmeyer flasks containing $250 \mathrm{ml}$ of sterile potato dextrose broth medium (Carl Roth $\mathrm{GmbH}+\mathrm{Co} \mathrm{KG}$ ) and incubated for 2 weeks at $22^{\circ} \mathrm{C}$ under constant shaking $(120 \mathrm{rpm})$ in the dark. Conidia suspensions were prepared the day of inoculation. Conidia were harvested by filtering through sterile gauze into 100-ml Erlenmeyer flasks. Spore concentrations were determined by using a hemocy-

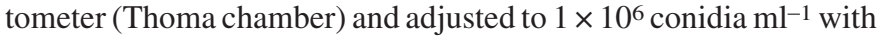
sterile tap water.
Seedling production and inoculation. Eleven different hosts were used, and the cultivar of each host is listed in Table 2. Artichoke, cotton, eggplant, lettuce, tomato, and watermelon experiments were performed at the UC Davis Contained Research Facility, a BSL3-P facility. For each species, one to two 128-plug trays (item CN-PLG 128; International Greenhouse Company, Danville, IL) containing autoclaved Sunshine Basic Mix number 2 potting mix (Sun Gro Horticulture, Agawam, MA) were seeded. Trays were incubated on a greenhouse bench with natural daylight at $21 \pm 5^{\circ} \mathrm{C}$, covered with sterilized cheesecloth until germination, and watered daily. Artichoke, cotton, eggplant, lettuce, and watermelon seedlings were grown for 4 weeks and tomato seedlings for 3 weeks prior to inoculation. During the first run of the experiment, fertilizer was applied daily for the first 2 weeks. During the second run, fertilizer was applied upon seeding and 2 weeks thereafter. Just prior to inoculation, seedlings were gently uprooted, rinsed free of soil in tap water, and immersed in $200 \mathrm{ml}$ of a conidial

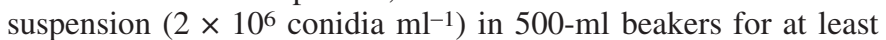
$15 \mathrm{~min}$ in groups of four representing the four replications of each of the 114 host-fungal strain combinations (6 hosts, 19 fungal strains). Inoculations were performed separately for each host species. Conidial suspensions were replaced approximately halfway through the inoculations to ensure that all hosts were inoculated with nearly the same conidial densities. Seedlings were planted into 0.5-liter (= 16 oz.) Styrofoam cups (item 16J16; Smart and Final, Inc., Commerce, CA) containing autoclaved Sunshine Basic Mix

TABLE 1. Verticillium strains used in this study

\begin{tabular}{|c|c|c|c|c|c|c|c|}
\hline Species & Lineage & Strain identifiers & $\begin{array}{c}\text { Host scientific } \\
\text { name }\end{array}$ & $\begin{array}{l}\text { Host common } \\
\text { name }\end{array}$ & Collection site & Strain origin $^{\mathrm{a}}$ & References \\
\hline V. longisporum ${ }^{\mathrm{b}}$ & $\mathrm{A} 1 / \mathrm{D} 1$ & $\begin{array}{l}\text { PD348, Bob.70, } \\
90-02\end{array}$ & $\begin{array}{l}\text { Brassica oleracea } \\
\text { var. botrytis }\end{array}$ & Cauliflower & Salinas, CA & Subbarao Lab Collection & 15 \\
\hline V. longisporum & A1/D1 & PD588, CA9 & B. oleracea & Cabbage & Gunman, Japan & $\begin{array}{l}\text { Subbarao Lab Collection } \\
\text { (Usami, Sakai) }\end{array}$ & 15 \\
\hline V. longisporum & A1/D1 & PD638, V140 & B. napus & Oilseed rape & $\begin{array}{l}\text { Mecklenburg, } \\
\text { Germany }\end{array}$ & UGoe & 15,32 \\
\hline V. longisporum ${ }^{\mathrm{b}, \mathrm{c}}$ & A1/D1 & PD639, V143 & B. napus & Oilseed rape & $\begin{array}{l}\text { Mecklenburg, } \\
\text { Germany }\end{array}$ & UGoe & $15,28,32$ \\
\hline V. longisporum & A1/D1 & $\begin{array}{l}\text { PD640, Chalons } \\
\text { en Champs }\end{array}$ & B. napus & Oilseed rape & France & UGoe & 15 \\
\hline V. longisporum ${ }^{\mathrm{d}}$ & A1/D1 & PD643, Vd02:50 & B. napus & Oilseed rape & Kölbäck, Sweden & UGoe & 15 \\
\hline V. longisporum & $\mathrm{A} 1 / \mathrm{D} 1$ & PD644, Vd4 & B. napus & Oilseed rape & Sweden & UGoe & 15,32 \\
\hline V. longisporum ${ }^{\mathrm{d}, \mathrm{e}}$ & A1/D1 & PD673, F617-9 & B. napus & Oilseed rape & $\begin{array}{l}\text { Haute-Marne, } \\
\text { France }\end{array}$ & $\begin{array}{l}\text { Subbarao Lab Collection } \\
\text { (Typas) }\end{array}$ & 15 \\
\hline V. longisporum ${ }^{\mathrm{b}}$ & $\mathrm{A} 1 / \mathrm{D} 2$ & PD356, Ar.139 & $\begin{array}{l}\text { Armoracia } \\
\text { rusticana }\end{array}$ & Horseradish & Illinois & Subbarao Lab Collection & 15 \\
\hline V. longisporum & $\mathrm{A} 1 / \mathrm{D} 2$ & PD402, Ar.136 & A. rusticana & Horseradish & Illinois & Subbarao Lab Collection & 15 \\
\hline V. longisporum ${ }^{\mathrm{b}}$ & $\mathrm{A} 1 / \mathrm{D} 2$ & PD629, 004 & A. rusticana & Horseradish & Illinois & $\begin{array}{l}\text { Subbarao Lab Collection } \\
\text { (Barbara) }\end{array}$ & 15 \\
\hline V. longisporum & A1/D2 & PD730, SDV-I066-08 & A. rusticana & Horseradish & Illinois & $\begin{array}{l}\text { Subbarao Lab Collection } \\
\text { (Babadoost) }\end{array}$ & 15 \\
\hline V. longisporum & A1/D3 & PD589, CA10 & B. oleracea & Cabbage & Gunman, Japan & $\begin{array}{l}\text { Subbarao Lab Collection } \\
\text { (Usami, Sakai) }\end{array}$ & 15 \\
\hline V. longisporum & A1/D3 & PD614, MD73 & B. napus & Oilseed rape & Germany & $\begin{array}{l}\text { Subbarao Lab Collection } \\
\text { (Barbara) }\end{array}$ & 15 \\
\hline V. longisporum ${ }^{\mathrm{b}, \mathrm{f}}$ & A1/D3 & $\begin{array}{l}\text { PD687, CBS 124.64, } \\
\text { MUCL } 9802\end{array}$ & A. rusticana & Horseradish & $\begin{array}{l}\text { Niedersachsen, } \\
\text { Germany }\end{array}$ & $\begin{array}{l}\text { Subbarao Lab Collection } \\
\text { (CBS) }\end{array}$ & 15 \\
\hline V. longisporum ${ }^{\mathrm{b}}$ & A1/D3 & $\begin{array}{l}\text { PD715, IPP } 0119, \\
\text { V132, lsp* }\end{array}$ & B. napus & Oilseed rape & $\begin{array}{l}\text { Mecklenburg, } \\
\text { Germany }\end{array}$ & UGoe & 15,32 \\
\hline V. dahliae $^{\mathrm{b}}$ & D2 & PD327, Ca.59, B, T2 & $\begin{array}{c}\text { Capsicum } \\
\text { аппиит }\end{array}$ & Bell pepper & Gilroy, CA & Subbarao Lab Collection & 15 \\
\hline V. dahliae de $^{\mathrm{b}}$ & D2 & PD502, Acer.875 & Acer sp. & Maple & Greenfield, WI & $\begin{array}{l}\text { Subbarao Lab Collection } \\
\text { (Stanosz) }\end{array}$ & 15 \\
\hline V. dahliae ${ }^{\mathrm{b}}$ & Main group & PD322, Ls.17 & Lactuca sativa & Lettuce & Watsonville, CA & Subbarao Lab Collection & 15 \\
\hline V. dahliae ${ }^{\mathrm{b}}$ & Main group & PD637, Vd73 & $\begin{array}{l}\text { Linum } \\
\text { usitatissimum }\end{array}$ & Common flax & $\begin{array}{l}\text { Mecklenburg, } \\
\text { Germany }\end{array}$ & UGoe & 15,32 \\
\hline
\end{tabular}


number 2. Three holes (7 $\mathrm{mm}$ in diameter) were punched into the bottom of each cup for drainage. An equal number of uninoculated controls were planted for each host. The experiment was conducted twice, with inoculations performed on 3 March 2012 and on 30 and 31 May 2012. Inoculated seedlings were returned to a greenhouse bench and arranged in a completely randomized block design, maintained for 2 months under daylight at $21 \pm 5^{\circ} \mathrm{C}$, and watered daily for the first week and every second day thereafter. Seedlings were watered individually by hand without splashing to minimize the risk of cross contamination. Fertilizer was applied daily for the first 3 weeks during the first run of the experiment, and upon planting and every second week thereafter during the repetition of the experiment. The exact amount of fertilizer applied is unknown but the fertilizer stock consisted of $\mathrm{CaNO}_{3}$, Grow More (Grow More Inc., Gardena, $\mathrm{CA}$ ), $\mathrm{KNO}_{3}, \mathrm{MgSO}_{4}$, and $\mathrm{MKP}$ and was in line with recommended rates for these crops.

Cabbage, cauliflower, horseradish, linseed, and oilseed rape seedlings were produced in a University of Göttingen climate chamber and greenhouse. Seed of cabbage, linseed, and oilseed rape were surface sterilized with $70 \%$ ethanol for $5 \mathrm{~s}$ and sown in sterile silica sand in seed trays ( 11 by 11 by $6 \mathrm{~cm}$ ). Cauliflower seedlings were treated the same way except that a 2:1 soil-sand mixture was used. Prior to inoculation, plants were incubated for 14 days in a climate chamber at $22^{\circ} \mathrm{C}, 70 \%$ relative humidity, and illuminated $14 \mathrm{~h}$ /day with a light source (Osram Lumilux T8 L58W/21-840) placed approximately $100 \mathrm{~cm}$ above the plants (light intensity: approximately $132 \mu \mathrm{mol} \mathrm{m} \mathrm{m}^{-2} \mathrm{~s}^{-1}$ ). Horseradish seedlings were generated vegetatively from fully developed plants approximately 30 to $40 \mathrm{~cm}$ in height (three seedlings per mature plant) and planted in pots ( 9 by 9 by $9 \mathrm{~cm}$ ) in a greenhouse using an autoclaved 3:2:1 mixture of compost soil-sand-turf. The horseradish seedlings were grown for 4 weeks in a greenhouse at $22^{\circ} \mathrm{C}$ with a day-and-night cycle of 14 and $10 \mathrm{~h}$, respectively, and a light intensity of approximately $82 \mu \mathrm{mol} \mathrm{m} \mathrm{m}^{-2} \mathrm{~s}^{-1}$ achieved by a light source (Osram Lumilux 54W/840) placed at approximately $150 \mathrm{~cm}$ from the plants.

Cabbage, cauliflower, linseed, and oilseed rape seedlings were inoculated by a cut-root dip inoculation method $(31,32)$. This involved careful uprooting of 14-day-old plants and removal of sand and soil particles under running tap water. Approximately one-third of the taproot was cut off and seedlings were dipped into a conidial

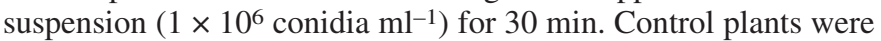
dipped into tap water for $30 \mathrm{~min}$. After inoculation, seedlings were transplanted into autoclaved 3:2:1 compost soil-sand-turf mixture in pots ( 7 by 7 by $7 \mathrm{~cm}$ ), with two seedlings in each pot. Inoculations with the 19 Verticillium isolates were performed separately for each host. Twenty seedlings per pathogen isolate were inoculated concurrently. Twenty seedlings per host served as control treatment. All plants were incubated for 6 weeks following inoculation.

Horseradish inoculations differed between the first and second experimental repetitions. The plants of the first repetition were first inoculated using the root dip method $(31,32)$ without clipping of the roots. Because of a lack of foliar symptoms, the same plants were reinoculated by injecting a maximum amount of conidia suspension into the upper part of the root with a 20-gauge hypodermic needle and a 2-ml syringe $(6,19)$. Tap water was injected into control plants. Plants of the second repetition were inoculated using root dip inoculation only. Only 10 Verticillium isolates and 12 horseradish seedlings were used for this experiment (Table 1). Inoculated horseradish plants were incubated for 9 weeks. Horseradish plants were fertilized weekly with a 1\% NPK solution (15:11:15\%).

Because 19 fungal isolates were tested on cabbage, cauliflower, linseed, and oilseed rape and 10 isolates on horseradish, there were 91 treatment combinations (isolates-plant species), including water controls. Treatments were arranged in a completely randomized block design with 20 replications for cabbage, cauliflower, linseed, and oilseed rape and 12 for horseradish. Plants were incubated under the same conditions as prior to inoculation. All experiments were performed twice.

TABLE 3. Mean disease incidence and disease score for the University of California (UC) Davis and University of Göttingen (UGoe) hosts across the two experimental replicates

\begin{tabular}{lcc}
\hline Host & Mean disease incidence $(\%)$ & Mean disease score \\
\hline UC Davis & & \\
Artichoke & 92 & 3.3 \\
Cotton & 76 & 1.8 \\
Eggplant & 99 & 4.0 \\
Lettuce & 66 & 1.5 \\
Tomato & 53 & 0.9 \\
Watermelon & 99 & 4.1 \\
Mean & 81 & 2.6 \\
UGoe & & \\
Cabbage & 77 & 1.0 \\
Cauliflower & 87 & 1.7 \\
Horseradish & 71 & 1.8 \\
Linseed & 32 & 0.8 \\
Oilseed rape & 72 & 1.8 \\
Mean & 68 & 1.4 \\
\hline
\end{tabular}

TABLE 2. Hosts used in this study

\begin{tabular}{|c|c|c|c|}
\hline Host common name & Host scientific name & Cultivar & Source $^{\mathrm{a}}$ \\
\hline Artichoke & Cynara scolymus $\mathrm{L}$. & 5473/91Blk & Subbarao Lab, UC Davis \\
\hline Cabbage & $\begin{array}{l}\text { Brassica oleracea convar. capitata } \\
\quad \text { var. alba L. }\end{array}$ & Brunswijker & $\begin{array}{l}\text { NBB egesa Gartencenter GmbH, Rodenberg, } \\
\text { Germany }\end{array}$ \\
\hline Cotton & Gossypium hirsutum L. & Acala Ultimate EF & Mike Davis Lab, UC Davis \\
\hline Eggplant & Solanum melongena $\mathrm{L}$. & Early Long Purple & Eden Brothers, Asheville, NC \\
\hline Horseradish & $\begin{array}{l}\text { Armoracia rusticana G. Gaertn., } \\
\text { B. Mey. \& Scherb. }\end{array}$ & $\ldots^{c}$ & $\begin{array}{l}\text { Rühlemann's Kräuter und Duftpflanzen, } \\
\text { Horstedt, Germany }\end{array}$ \\
\hline Oilseed rape & B. napus L. var. oleifera D.C. ${ }^{\mathrm{d}}$ & Falcon & $\begin{array}{l}\text { Norddeutsche Pflanzenzucht Hans-Georg } \\
\text { Lembke KG, Hohenlieth/Malchow, } \\
\text { Germany }\end{array}$ \\
\hline Tomato & S. lycopersicum L. & Earlypak 7 & Subbarao Lab, UC Davis \\
\hline Watermelon & Citrullus lanatus (Thunb.) Matsum. \& Nakai & Sugar Baby & Eden Brothers, Asheville, NC \\
\hline
\end{tabular}


Disease assessment. Artichoke, cotton, eggplant, lettuce, tomato, and watermelon. Cups were removed and root systems were cleared of soil by shaking. External symptoms were noted. Roots and shoots were cut open with a scalpel parallel to the long axis to evaluate vascular discoloration, and a disease score of 0 to 5 was assigned to each plant. The disease severity rating system was based on Vallad et al. (29) but generalized to fit all hosts as follows: $0=$ vascular discoloration absent; $1=$ discoloration of taproot tip only; 2 = discoloration of the taproot not beyond crown; $3=$ discoloration beyond crown into shoot; $4=$ discoloration throughout taproot and shoot, up to several leaves wilted, plants possibly stunted; and $5=$ discoloration throughout taproot and stem, all leaves wilted or plant dead. Koch's postulates were performed on one inoculated and one control plant per hostisolate combination for the first repetition of the experiment. Side roots and remaining soil were removed and taproots were cut into five pieces that were sterilized in $10 \%$ bleach (sodium hypochlorite $0.6 \%$ ) for $1 \mathrm{~min}$, rinsed twice in sterilized water, dried on sterile paper towels, plated onto Verticillium semiselective NP-10 medium $(18,26)$, and examined for the presence of microsclerotia
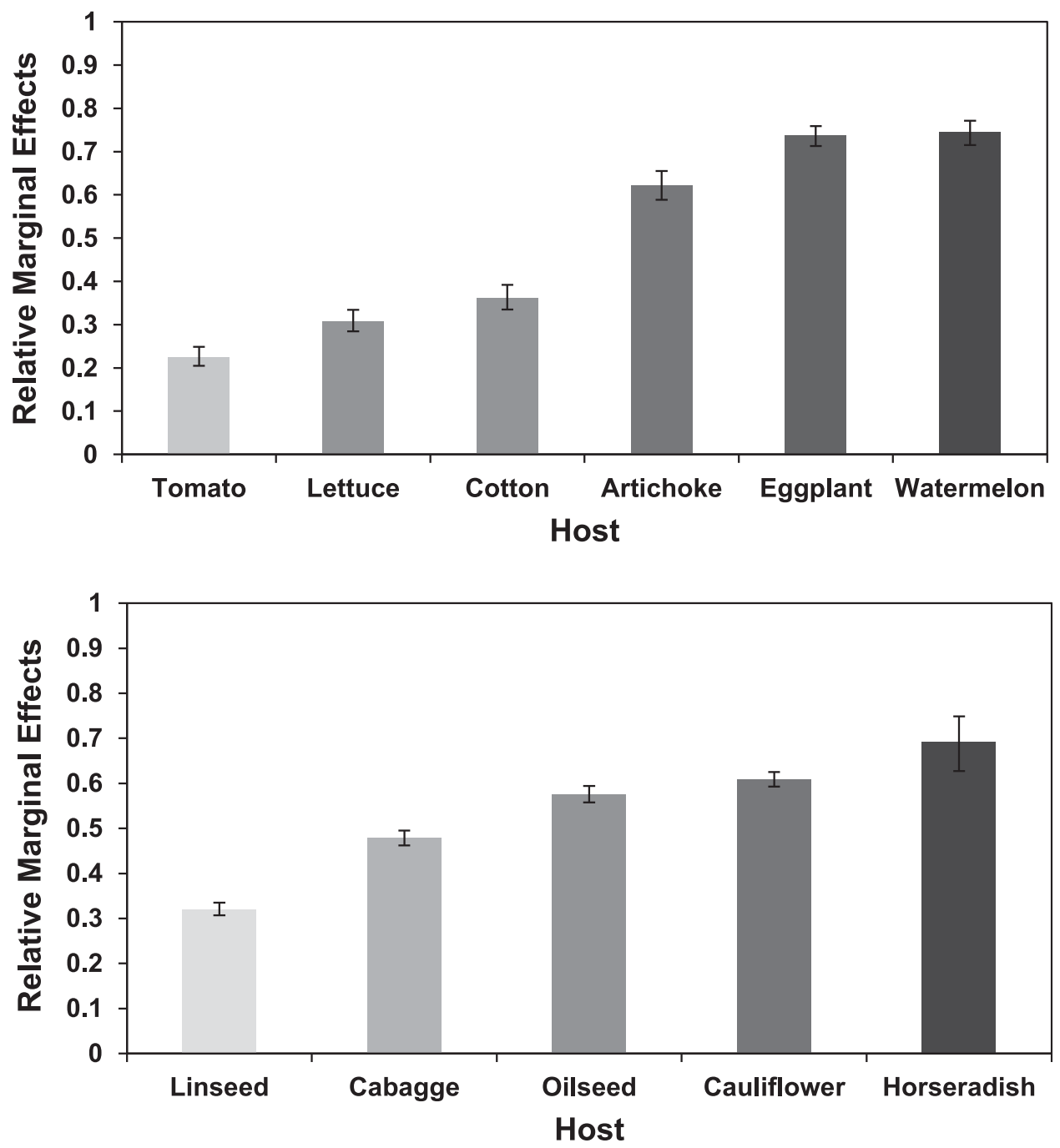

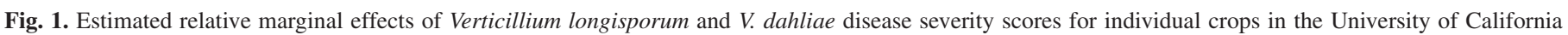
Davis (top) and University of Göttingen (bottom) experiments; 95\% confidence intervals are indicated by vertical lines.

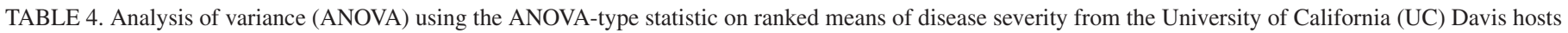
and the University of Göttingen hosts ${ }^{\mathrm{a}}$

\begin{tabular}{|c|c|c|c|c|c|c|c|c|}
\hline \multirow[b]{2}{*}{ Effect } & \multicolumn{4}{|c|}{ UC Davis hosts } & \multicolumn{4}{|c|}{ University of Göttingen hosts } \\
\hline & $\mathrm{df}_{\mathrm{Num}}$ & $\mathrm{df}_{\text {Den }}$ & ATS & $P$ value & $\mathrm{df}_{\mathrm{Num}}$ & $\mathrm{df}_{\text {Den }}$ & ATS & $P$ value \\
\hline Host & 4.35 & 571 & 378.83 & $<0.0001$ & 2.28 & 245 & 194.76 & $<0.0001$ \\
\hline Isolate & 18.00 & 571 & 9.87 & $<0.0001$ & 17.5 & 1400 & 50.23 & $<0.0001$ \\
\hline Replication (Experiment) & 6.00 & 593 & 9.31 & $<0.0001$ & 37 & 2481 & 0.9 & 0.6454 \\
\hline Host $\times$ isolate & 78.20 & 571 & 5.32 & $<0.0001$ & 49.3 & 725 & 11.45 & $<0.0001$ \\
\hline Experiment $(n=2)$ & 1.00 & 571 & 1.01 & 0.3151 & 1 & 2423 & 5.27 & 0.0217 \\
\hline Host $\times$ experiment & 4.35 & 571 & 17.90 & $<0.0001$ & 2.97 & 2422 & 8.54 & $<0.0001$ \\
\hline Experiment $\times$ isolate & 18.00 & 571 & 2.18 & 0.0026 & 14.9 & 2420 & 3.26 & $<0.0001$ \\
\hline Host $\times$ experiment $\times$ isolate & 78.20 & 571 & 1.20 & 0.114 & 42.5 & 2431 & 5.76 & $<0.0001$ \\
\hline
\end{tabular}

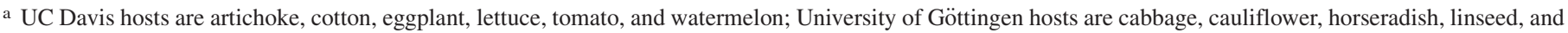
oilseed rape. 
in culture medium using a dissecting microscope 1 to 2 weeks after plating.

Cauliflower, cabbage, horseradish, linseed, and oilseed rape. Vascular discoloration was assessed as a measure of disease severity. Cauliflower, cabbage, linseed, and oilseed rape plants were removed from the pots, soil was washed off under running tap water and roots were sliced vertically with a scalpel. Discoloration was rated as follows, according to Vallad et al. (29): $0=$ no vascular discoloration, $1=25 \%$ of vascular tissues in tap root exhibiting discoloration, $2=26$ to $50 \%$ of vascular tissues in tap root exhibiting discoloration, $3=51$ to $75 \%$ of vascular tissues in tap root exhibiting discoloration, $4=76$ to $100 \%$ of vascular tissues in tap root exhibiting discoloration, and $5=100 \%$ of vascular tissues in tap root exhibiting discoloration extending into crown.

For horseradish, roots were cut horizontally with a sharp knife approximately 1.5 to $2 \mathrm{~cm}$ below the hypocotyl, and the vascular discoloration of root-cross sections was rated following the method by Khan et al. (20).

Statistical analysis. The Verticillium disease severity scores represented ordinal data that were analyzed using a nonparametric approach where the effects of experimental factors, including fungal strain and host, on disease severity scores were quantified through estimated relative marginal effects (RME) $(5,24)$. Null hypotheses of treatments having no effect were tested using the analysis of variance-type statistic (ATS). Linear contrasts were constructed to compare disease severities between groups of
TABLE 5. Mean disease scores for Verticillium dahliae and V. longisporum isolates across all University of California (UC) Davis and University of Göttingen (UGoe) hosts

\begin{tabular}{lccc}
\hline & & \multicolumn{2}{c}{ Mean disease scores $^{\mathrm{a}}$} \\
\cline { 3 - 4 } Lineage or species & Isolate & UC Davis hosts & UGoe hosts \\
\hline V. dahliae & PD322 & $\mathbf{3 . 7}$ & 0.7 \\
$V$. dahliae & PD327 & 3.2 & 0.6 \\
$V$. dahliae & PD502 & 3.4 & $\mathbf{0 . 6}$ \\
$V$. dahliae & PD637 & 2.8 & 0.9 \\
A1/D1 & PD348 & 2.6 & 2.0 \\
A1/D1 & PD588 & 2.3 & 1.2 \\
A1/D1 & PD638 & 2.5 & 2.2 \\
A1/D1 & PD639 & 2.3 & 1.3 \\
A1/D1 & PD640 & 2.3 & 0.9 \\
A1/D1 & PD643 & 2.7 & 2.3 \\
A1/D1 & PD644 & $\mathbf{2 . 2}$ & 0.9 \\
A1/D1 & PD673 & 2.4 & $\ldots .8$ \\
A1/D2 & PD356 & 2.5 & 0.8 \\
A1/D2 & PD402 & 2.5 & 1.1 \\
A1/D2 & PD629 & 2.5 & 1.2 \\
A1/D2 & PD730 & 2.6 & $\mathbf{2 . 7}$ \\
A1/D3 & PD589 & 2.5 & 1.2 \\
A1/D3 & PD614 & 2.3 & 0.7 \\
A1/D3 & PD687 & $\ldots$ & \\
A1/D3 & PD715 & 2.5 &
\end{tabular}

${ }^{a}$ UC Davis hosts are artichoke, cotton, eggplant, lettuce, tomato, and watermelon; UGoe hosts are cabbage, cauliflower, horseradish, linseed, and oilseed rape. Highest and lowest scores for each location are in bold.
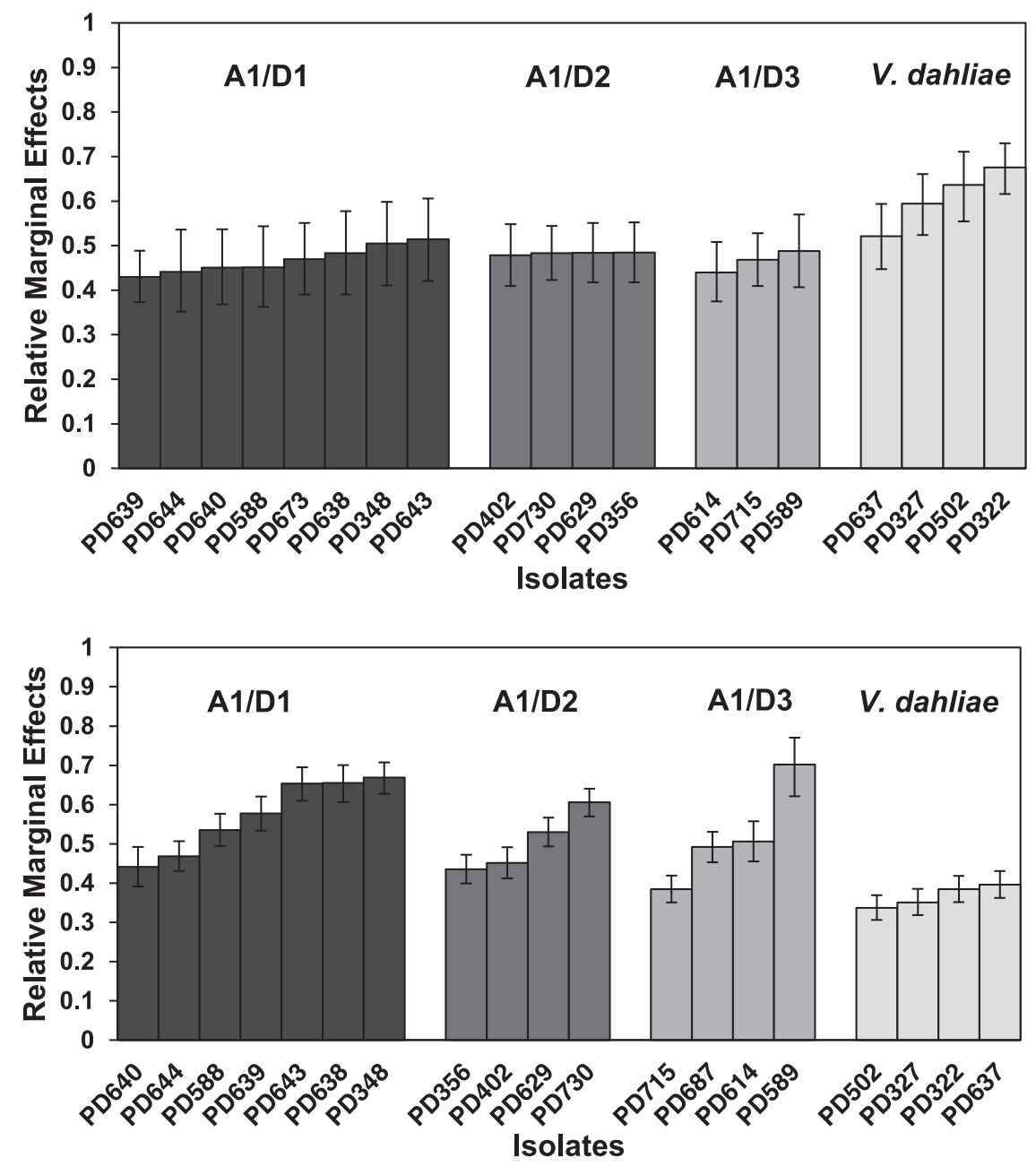

Fig. 2. Estimated relative marginal effects of virulence across all individual Verticillium dahliae and V. longisporum isolates grouped according to affiliation with $V$. longisporum lineages A1/D1, A1/D2, and A1/D3 and V. dahliae, for the University of California (UC) Davis hosts (top) and the University of Göttingen hosts (bottom); 95\% confidence intervals are provided. UC Davis hosts are artichoke, cotton, eggplant, lettuce, tomato, and watermelon; University of Göttingen hosts are cabbage, cauliflower, horseradish, linseed, and oilseed rape. 
isolates representing the $V$. longisporum lineages and $V$. dahliae, and to assess susceptibility to Verticillium infection between different hosts.

Calculations were performed using the PROC Mixed procedure in SAS (2010, version 9.3) to generate RME and the LD_CI macro to generate $95 \%$ confidence intervals $(5,24)$. The RME values are generated by the equation $\mathrm{RME}=(R-0.5) / N$, where $R$ is the mean treatment ranking and $N$ is the total number of experimental units in the analysis. Replications nested within experiments were considered random effects in the analysis.

The UC Davis and the University of Göttingen data were analyzed separately. Differences between isolates and hosts (fixed effects) were determined for the UC Davis crops artichoke, cotton, eggplant, lettuce, tomato, and watermelon and for the University of Göttingen crops cabbage, cauliflower, horseradish, linseed, and oilseed rape. For each crop, differences between individual isolates, between $V$. longisporum lineages, and between $V$. longisporum lineages and $V$. dahliae were determined. The same differences were also assessed for the collective Brassicaceae crops and the collective non-Brassicaceae crops, except linseed, which was excluded because linseed scores were obtained at the University of Göttingen with a different rating scale.

\section{RESULTS}

Artichoke, cotton, eggplant, lettuce, tomato, and watermelon. Verticillium disease symptoms were observed on all hosts. Mean disease incidence, which is the percentage of plants with Verticillium disease symptoms, ranged from $99 \%$ in eggplant and watermelon to $53 \%$ in tomato. Mean disease scores across all isolates were highest for eggplant and watermelon, with 4.0 and 4.1, respectively, and lowest for tomato, with 1.0. The mean disease incidence across all hosts was $81 \%$ and the mean disease score was 2.6 (Table 3). RME of disease severity of hosts across all isolates of $V$. dahliae and V. longisporum showed significant differences (Fig. $1)$. The ATS of the RME showed that the effect of host was significant $(P<0.0001)$ (Table 4$)$.

There were differences in virulence between isolates combined across all hosts tested at UC Davis. V. dahliae strain PD322 was the most virulent isolate, with a mean disease score of 3.7, whereas $V$. longisporum lineage A1/D1 strain PD644 was the least virulent isolate, with a mean disease score of 2.2 (Table 5). Virulence score RME of individual isolates across all hosts is shown in Figure 2, and indicates significant differences between some isolates. The ATS of the RME shows that the effect of isolate was significant $(P<0.0001)$ (Table 4).

On individual hosts, the highest disease score means observed were 5 for $V$. dahliae strains PD322 on watermelon and PD502 on artichoke. V. longisporum lineages A1/D1 strains PD348 and PD643 on eggplant and PD638 and on watermelon also had disease score means of 5 . The lowest score was 0 , by $V$. longisporum lineage A1/D1 strains PD348 and PD644 on tomato (Supplementary Table $\mathrm{S} 1)$. The isolate RME on individual crops are shown in Figure 3. The effect of isolate was significant for all hosts $(P<0.0001)$ (Supplementary Table S2).

There were significant differences in virulence between Verticillium spp. and lineages across all hosts combined $(P<0.0001)$ (Table 6$)$. $V$. dahliae was the most virulent group, with an overall disease score of 3.3, which was higher than the scores of the $V$. longisporum lineages, which varied between 2.4 and 2.5 (Table 7; Fig. 4).

On individual hosts, $V$. dahliae was significantly more virulent than $V$. longisporum on artichoke and cotton $(P<0.0001)$ but not significantly different from $V$. longisporum lineage A1/D1 on watermelon $(P=0.57), V$. longisporum lineages A1/D2 and A1/D3 on lettuce $(P>0.14)$, and $V$. longisporum lineage A1/D2 on tomato $(P=0.09)$. V. dahliae was significantly less virulent than $V$. longisporum lineage A1/D1 on eggplant $(P<0.0001)$ (Table 8; Fig. 5).
Within species and lineages across all hosts combined, there were no significant virulence differences between isolates, except in V. dahliae, where strain PD322 was more virulent than strain PD637 (Fig. 2). On individual hosts within species and lineages, there were virulence differences between isolates but no single isolate was consistently most or least virulent across all hosts (Fig. 3). This
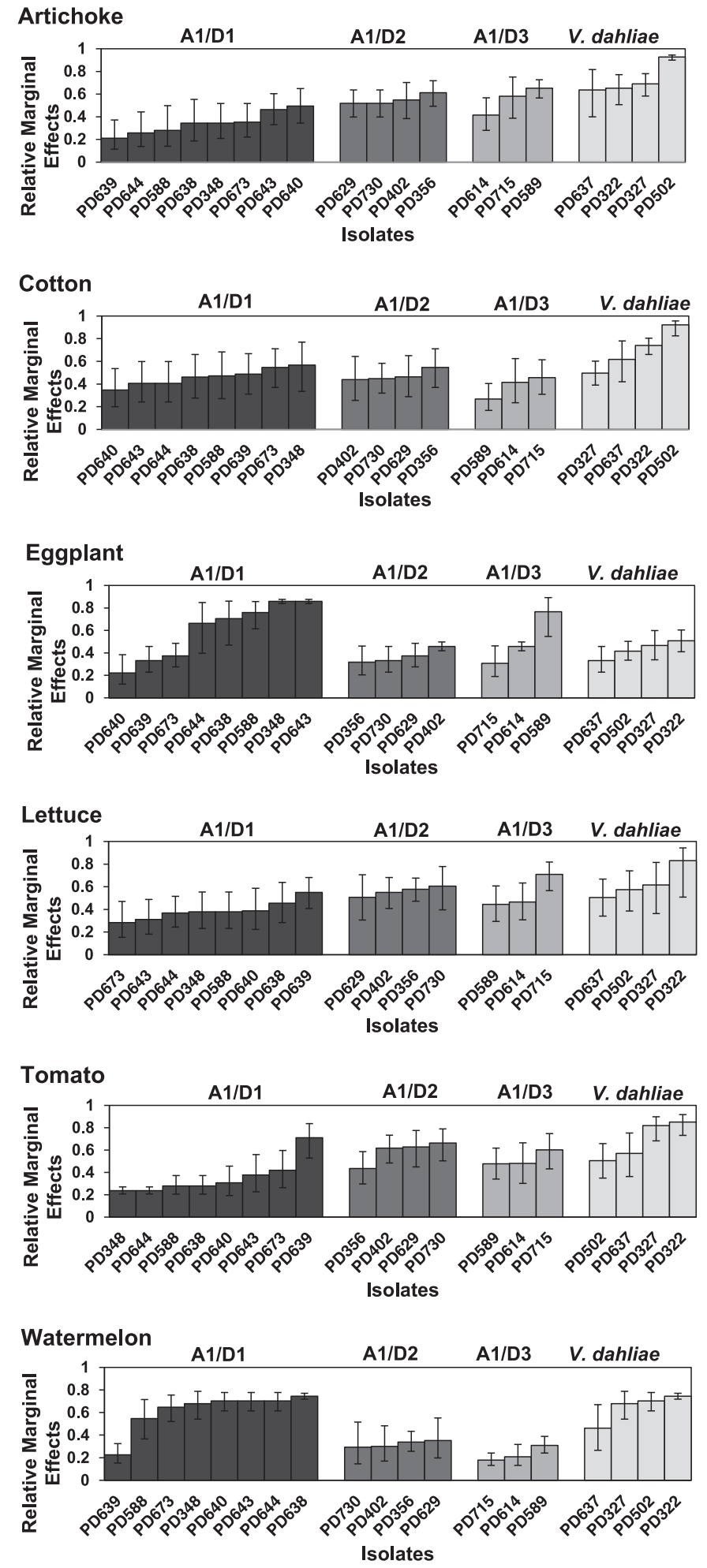

Fig. 3. Estimated relative marginal effects of virulence of individual Verticillium dahliae and Verticillium longisporum isolates on University of California (UC) Davis hosts grouped according to affiliation with $V$. longisporum lineages A1/D1, A1/D2, and A1/D3 and V. dahlia; 95\% confidence intervals are provided. UC Davis hosts are artichoke, cotton, eggplant, lettuce, tomato, and watermelon. 
agrees with the significant host-isolate interaction (Table 4), which indicates that isolate virulence is host dependent.

Cabbage, cauliflower, horseradish, linseed, and oilseed rape. Verticillium disease symptoms were observed on all hosts. Mean disease incidence ranged from $87 \%$ in cauliflower to $32 \%$ in linseed. Mean disease scores across all isolates were highest for horseradish and oilseed rape, with 1.8, and lowest for linseed, with 0.8 . The mean disease incidence across all hosts was $68 \%$ and the mean disease score was 1.4 (Table 3). RME suggested significant differences in the response of hosts to all strains of $V$. dahliae and $V$. longisporum (Fig. 1). The ATS of the RME showed that the effect of host was significant $(P<0.0001)$ (Table 4$)$.
TABLE 7. Mean disease scores for Verticillium dahliae and V. longisporum lineages across all University of California (UC) Davis and University of Göttingen hosts

\begin{tabular}{lcc}
\hline & \multicolumn{2}{c}{ Mean disease scores } \\
\cline { 2 - 3 } Lineage or species & UC Davis hosts & University of Göttingen hosts \\
\hline A1/D1 & 2.4 & $\mathbf{1 . 7}$ \\
A1/D2 & 2.5 & 1.2 \\
A1/D3 & $\mathbf{2 . 4}$ & 1.4 \\
V. dahliae & $\mathbf{3 . 3}$ & $\mathbf{0 . 8}$ \\
\hline
\end{tabular}

a UC Davis hosts are artichoke, cotton, eggplant, lettuce, tomato, and watermelon; University of Göttingen hosts are cabbage, cauliflower, horseradish, linseed, and oilseed rape. Highest and lowest scores for each location are in bold.

TABLE 6. Analysis of variance (ANOVA) using the ANOVA-type statistic on ranked means of disease severity grouped according to Verticillium dahliae and V. longisporum lineages across the University of California (UC) Davis and the University of Göttingen hosts

\begin{tabular}{|c|c|c|c|c|c|c|c|c|}
\hline \multirow[b]{2}{*}{ Effect } & \multicolumn{4}{|c|}{ UC Davis hosts } & \multicolumn{4}{|c|}{ University of Göttingen hosts } \\
\hline & $\mathrm{df}_{\mathrm{Num}}$ & $\mathrm{df}_{\text {Den }}$ & ATS & $P$ value & $\mathrm{df}_{\mathrm{Num}}$ & $\mathrm{df}_{\text {Den }}$ & ATS & $P$ value \\
\hline Host & 4.84 & 530 & 257.19 & $<0.0001$ & 2.28 & 245 & 194.76 & $<0.0001$ \\
\hline Lineage or species & 2.91 & 530 & 37.56 & $<0.0001$ & 17.50 & 1400 & 50.23 & $<0.0001$ \\
\hline Replication (Experiment) & 6.00 & 662 & 7.46 & $<0.0001$ & 37.00 & 2481 & 0.90 & 0.6454 \\
\hline Host $\times$ lineage or species & 12.90 & 530 & 10.29 & $<0.0001$ & 49.30 & 725 & 11.45 & $<0.0001$ \\
\hline Experiment & 1.00 & 530 & 1.19 & 0.2747 & 1.00 & 2423 & 5.27 & 0.0217 \\
\hline Host $\times$ experiment & 4.84 & 530 & 13.53 & $<0.0001$ & 2.97 & 2422 & 8.54 & $<0.0001$ \\
\hline Experiment $\times$ lineage or species & 2.91 & 530 & 1.72 & 0.1612 & 14.90 & 2420 & 3.26 & $<0.0001$ \\
\hline Host $\times$ experiment $\times$ lineage or species & 12.9 & 530 & 1.26 & 0.2298 & 42.50 & 2431 & 5.76 & $<0.0001$ \\
\hline
\end{tabular}

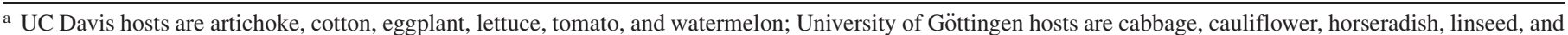
oilseed rape.
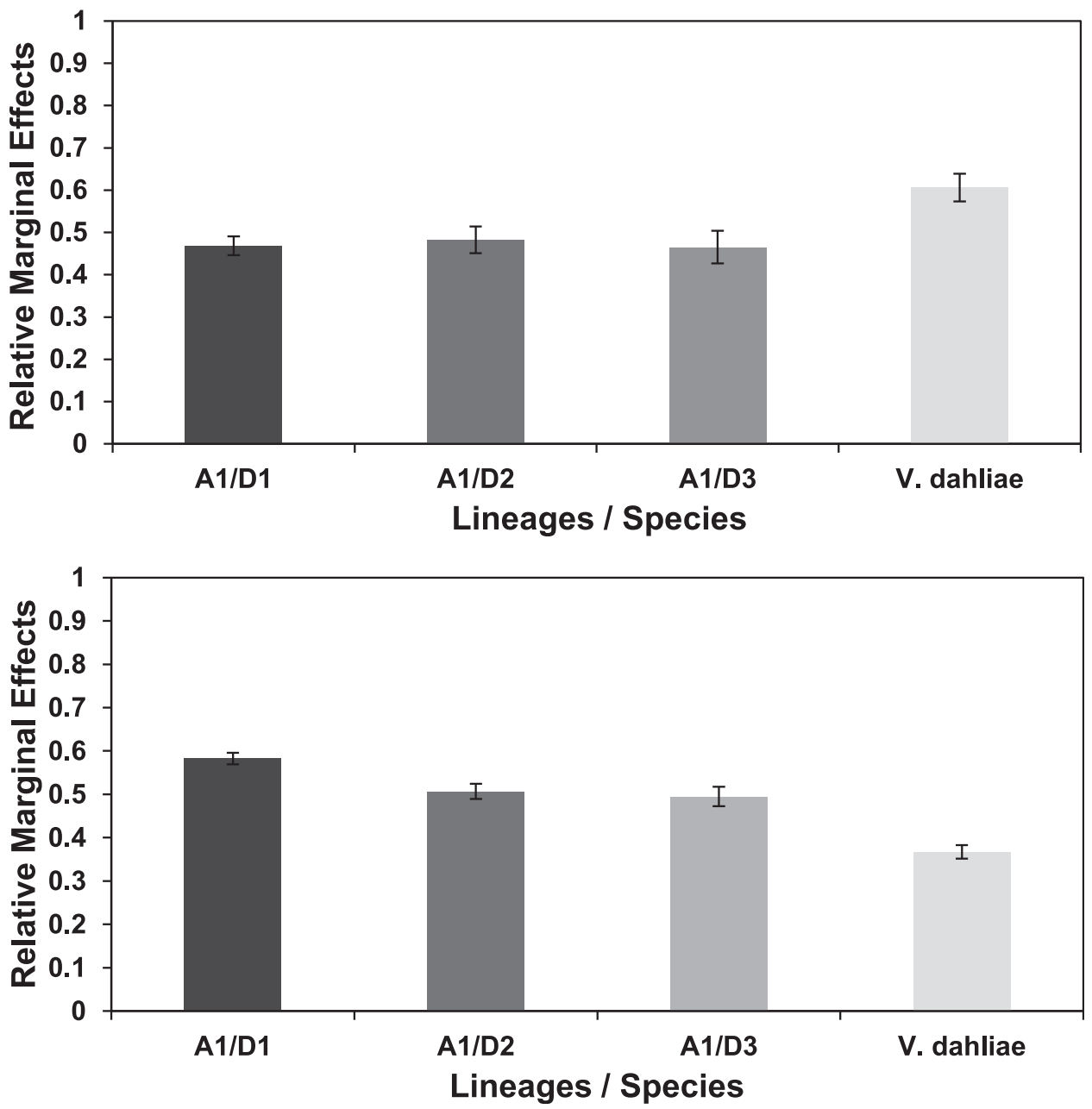

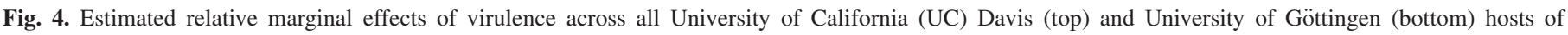

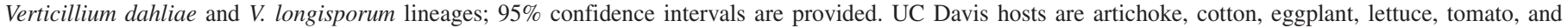
watermelon; University of Göttingen hosts are cabbage, cauliflower, horseradish, linseed, and oilseed rape. 
TABLE 8. Contrasts between disease severity of Verticillium dahliae and V. longisporum lineages on individual University of California (UC) Davis hosts, University of Göttingen (UGoe) hosts, and the Brassicaceae hosts onlya

\begin{tabular}{|c|c|c|c|c|}
\hline Location, host, effect & Num DF & Den DF & Value & $P>F$ \\
\hline \multicolumn{5}{|l|}{ UC Davis } \\
\hline \multicolumn{5}{|l|}{ Artichoke } \\
\hline A1/D1 vs. A1/D2 & 1 & 79.7 & 24.87 & $<0.0001$ \\
\hline A1/D1 vs. A1/D3 & 1 & 42.4 & 14.29 & 0.0002 \\
\hline A1/D1 vs. V. dahliae & 1 & 62.9 & 56.74 & $<0.0001$ \\
\hline A1/D2 vs. A1/D3 & 1 & 35.2 & 0 & 0.9984 \\
\hline A1/D2 vs. $V$. dahliae & 1 & 51.8 & 13.26 & 0.0003 \\
\hline A1/D3 vs. $V$. dahliae & 1 & 46.9 & 8.65 & 0.0033 \\
\hline \multicolumn{5}{|l|}{ Cotton } \\
\hline A1/D1 vs. A1/D2 & 1 & 62 & 0.06 & 0.8045 \\
\hline A1/D1 vs. A1/D3 & 1 & 36.3 & 1.96 & 0.1615 \\
\hline A1/D1 vs. $V$. dahliae & 1 & 63.8 & 21.48 & $<0.0001$ \\
\hline A1/D2 vs. A1/D3 & 1 & 40.3 & 2.23 & 0.1353 \\
\hline A1/D2 vs. V. dahliae & 1 & 59.1 & 15.77 & $<0.0001$ \\
\hline A1/D3 vs. $V$. dahliae & 1 & 38.8 & 24.66 & $<0.0001$ \\
\hline Eggplant & & & & \\
\hline A1/D1 vs. A1/D2 & 1 & 86 & 25.09 & $<0.0001$ \\
\hline A1/D1 vs. A1/D3 & 1 & 44 & 1.63 & 0.2018 \\
\hline A1/D1 vs. V. dahliae & 1 & 87.9 & 11.84 & 0.0006 \\
\hline A1/D2 vs. A1/D3 & 1 & 29.7 & 5.46 & 0.0195 \\
\hline A1/D2 vs. V. dahliae & 1 & 54 & 2.56 & 0.1097 \\
\hline A1/D3 vs. $V$. dahliae & 1 & 33.4 & 1.65 & 0.1987 \\
\hline Lettuce & & & & \\
\hline A1/D1 vs. A1/D2 & 1 & 70.7 & 17.68 & $<0.0001$ \\
\hline A1/D1 vs. A1/D3 & 1 & 36.7 & 8.69 & 0.0032 \\
\hline A1/D1 vs. $V$. dahliae & 1 & 50.7 & 22.58 & $<0.0001$ \\
\hline A1/D2 vs. A1/D3 & 1 & 39.3 & 0.14 & 0.7124 \\
\hline A1/D2 vs. V. dahliae & 1 & 51.8 & 1.8 & 0.1797 \\
\hline A1/D3 vs. V. dahliae & 1 & 47.1 & 2.18 & 0.1402 \\
\hline Tomato & & & & \\
\hline A1/D1 vs. A1/D2 & 1 & 62.3 & 24.84 & $<0.0001$ \\
\hline A1/D1 vs. A1/D3 & 1 & 49.2 & 14.4 & 0.0001 \\
\hline A1/D1 vs. V. dahliae & 1 & 50 & 37.39 & $<0.0001$ \\
\hline A1/D2 vs. A1/D3 & 1 & 48.6 & 1.79 & 0.1812 \\
\hline A1/D2 vs. V. dahliae & 1 & 54.1 & 2.88 & 0.0895 \\
\hline A1/D3 vs. $V$. dahliae & 1 & 46.6 & 8.57 & 0.0034 \\
\hline Watermelon & & & & \\
\hline A1/D1 vs. A1/D2 & 1 & 56.4 & 37.72 & $<0.0001$ \\
\hline A1/D1 vs. A1/D3 & 1 & 63.9 & 109.05 & $<0.0001$ \\
\hline A1/D1 vs. V. dahliae & 1 & 57.9 & 0.33 & 0.5654 \\
\hline A1/D2 vs. A1/D3 & 1 & 46.7 & 3.55 & 0.0597 \\
\hline A1/D2 vs. V. dahliae & 1 & 57 & 34.9 & $<0.0001$ \\
\hline A1/D3 vs. $V$. dahliae & 1 & 45 & 83.85 & $<0.0001$ \\
\hline University of Göttingen ho & & & & \\
\hline Cabbage & & & & \\
\hline A1/D1 vs. A1/D2 & 1 & 274 & 27.65 & $<0.0001$ \\
\hline A1/D1 vs. A1/D3 & 1 & 91.6 & 0.93 & 0.3345 \\
\hline A1/D1 vs. V. dahliae & 1 & 350 & 0.27 & 0.6042 \\
\hline A1/D2 vs. A1/D3 & 1 & 124 & 9.22 & 0.0024 \\
\hline A1/D2 vs. V. dahliae & 1 & 263 & 31.66 & $<0.0001$ \\
\hline A1/D3 vs. V. dahliae & 1 & 93.9 & 1.71 & 0.1911 \\
\hline Cauliflower & & & & \\
\hline A1/D1 vs. A1/D2 & 1 & 313 & 31.5 & $<0.0001$ \\
\hline A1/D1 vs. A1/D3 & 1 & 213 & 5.41 & 0.02 \\
\hline A1/D1 vs. V. dahliae & 1 & 334 & 112.88 & $<0.0001$ \\
\hline A1/D2 vs. A1/D3 & 1 & 192 & 4.79 & 0.0286 \\
\hline A1/D2 vs. V. dahliae & 1 & 258 & 25.85 & $<0.0001$ \\
\hline A1/D3 vs. $V$. dahliae & 1 & 182 & 40.48 & $<0.0001$ \\
\hline Horseradish & & & & \\
\hline A1/D1 vs. A1/D2 & 1 & 26.5 & 27.05 & $<0.0001$ \\
\hline A1/D1 vs. A1/D3 & 1 & 20.4 & 3.06 & 0.0802 \\
\hline A1/D1 vs. $V$. dahliae & 1 & 35.8 & 12.56 & 0.0004 \\
\hline A1/D2 vs. A1/D3 & 1 & 13.9 & 27.45 & $<0.0001$ \\
\hline A1/D2 vs. V. dahliae & 1 & 38.3 & 137.73 & $<0.0001$ \\
\hline A1/D3 vs. V. dahliae & 1 & 17 & 0.29 & 0.5929 \\
\hline Linseed & & & & \\
\hline A1/D1 vs. A1/D2 & 1 & 306 & 2.9 & 0.0885 \\
\hline A1/D1 vs. A1/D3 & 1 & 267 & 20.38 & $<0.0001$ \\
\hline A1/D1 vs. V. dahliae & 1 & 348 & 24.21 & $<0.0001$ \\
\hline A1/D2 vs. A1/D3 & 1 & 256 & 30.98 & $<0.0001$ \\
\hline A1/D2 vs. $V$. dahliae & 1 & 284 & 35.13 & $<0.0001$ \\
\hline A1/D3 vs. V. dahliae & 1 & 218 & 0.07 & 0.7927 \\
\hline Oilseed rape & & & & \\
\hline A1/D1 vs. A1/D2 & 1 & 344 & 161.41 & $<0.0001$ \\
\hline A1/D1 vs. A1/D3 & 1 & 230 & 61.33 & $<0.0001$ \\
\hline A1/D1 vs. $V$. dahliae & 1 & 362 & 283.13 & $<0.0001$ \\
\hline A1/D2 vs. A1/D3 & 1 & 190 & 6.39 & 0.0115 \\
\hline A1/D2 vs. V. dahliae & 1 & 270 & 20.14 & $<0.0001$ \\
\hline A1/D3 vs. V. dahliae & 1 & 190 & 36.52 & $<0.0001$ \\
\hline Brassicaceae hosts & & & & \\
\hline A1/D1 vs. A1/D2 & 1 & 1070 & 83.49 & $<0.0001$ \\
\hline A1/D1 vs. A1/D3 & 1 & 673 & 59.87 & $<0.0001$ \\
\hline A1/D1 vs. V. dahliae & 1 & 1145 & 411.32 & $<0.0001$ \\
\hline A1/D2 vs. A1/D3 & 1 & 654 & 0.09 & 0.7593 \\
\hline A1/D2 vs. V. dahliae & 1 & 906 & 105.02 & $<0.0001$ \\
\hline A1/D3 vs. V. dahliae & 1 & 608 & 86.84 & $<0.0001$ \\
\hline
\end{tabular}

${ }^{a}$ Brassicaceae hosts are cabbage, cauliflower, horseradish, and oilseed rape.
There were differences in virulence between isolates across all hosts combined. V. longisporum lineage A1/D3 strain PD589 was overall the most virulent isolate, with a mean disease score of 2.7, whereas $V$. dahliae strains PD327 and PD502 were least virulent, with a mean disease score of 0.6 (Table 5). Virulence score RME of individual isolates (Fig. 2) across all hosts indicated significant differences between some isolates. The ATS of the RME shows that the effect of isolate was significant $(P<0.0001)$ (Table 4$)$.

On individual hosts, the highest disease score was 4.6 for V. longisporum lineage A1/D3 strain PD589 on oilseed rape. The lowest score was 0 by $V$. dahliae strains PD322 and PD327 and $V$. longisporum lineage A1/D1 strain PD588, all on linseed (Supplementary Table S3). The isolate RME on individual crops are shown in Figure 6. The effect of isolate was significant for all hosts $(P<0.0001)$ (Supplementary Table S4).

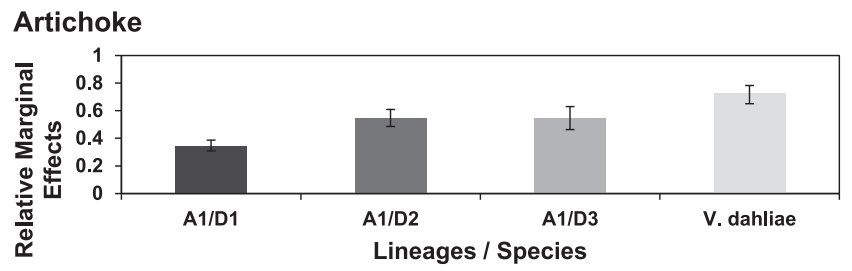

Cotton

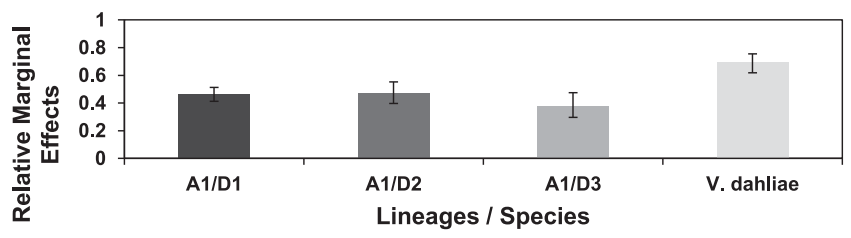

Eggplant

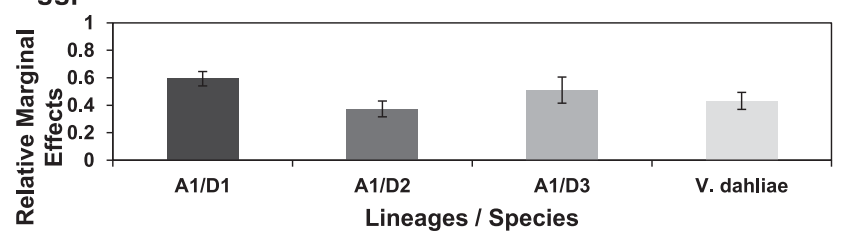

Lettuce

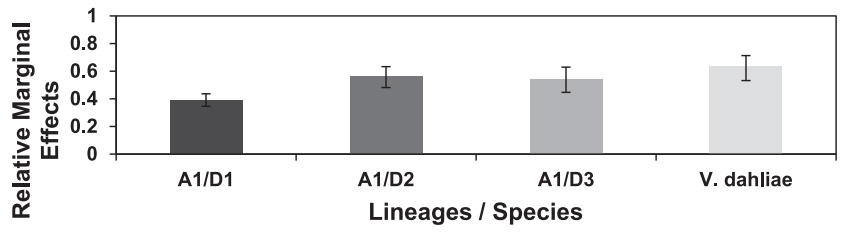

Tomato

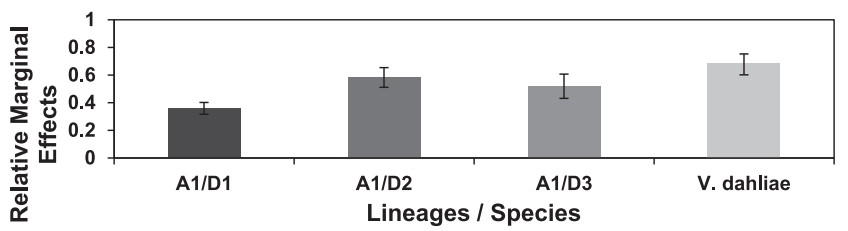

Watermelon

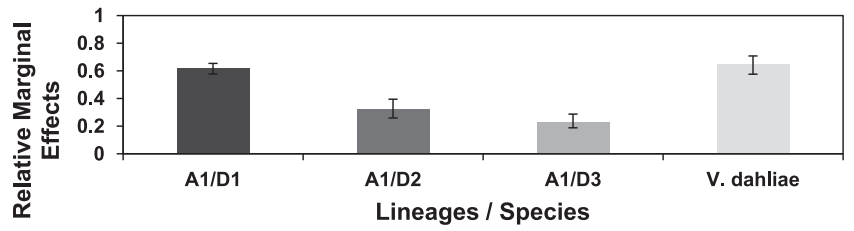

Fig. 5. Estimated relative marginal effects of virulence on individual University of California Davis hosts of Verticillium dahliae and V. longisporum lineages; $95 \%$ confidence intervals are provided. 
There were significant differences in virulence between Verticillium spp. and lineages across all hosts combined (Table 7). $V$. longisporum lineage A1/D1 was the most virulent group, with an overall disease score of 1.7 , followed by $V$. longisporum lineages A1/D3 and A1/D2, with scores of 1.4 and 1.2, respectively, which was significantly higher than the score of $V$. dahliae $(P<0.0001)$, which was 0.8 (Table 7; Fig. 4).
On individual hosts, $V$. longisporum lineage A1/D1 was significantly more virulent than other lineages and $V$. dahliae on cauliflower $(P=0.02)$ and oilseed rape $(P<0.0001)$, and equally virulent as $V$. longisporum lineage A1/D2 on linseed $(P=0.0885)$. $V$. longisporum lineage A1/D2 was significantly more virulent than other lineages and $V$. dahliae on cabbage $(P<0.0001)$ and horseradish $(P<0.0001)$ (Table 8; Fig. 7).
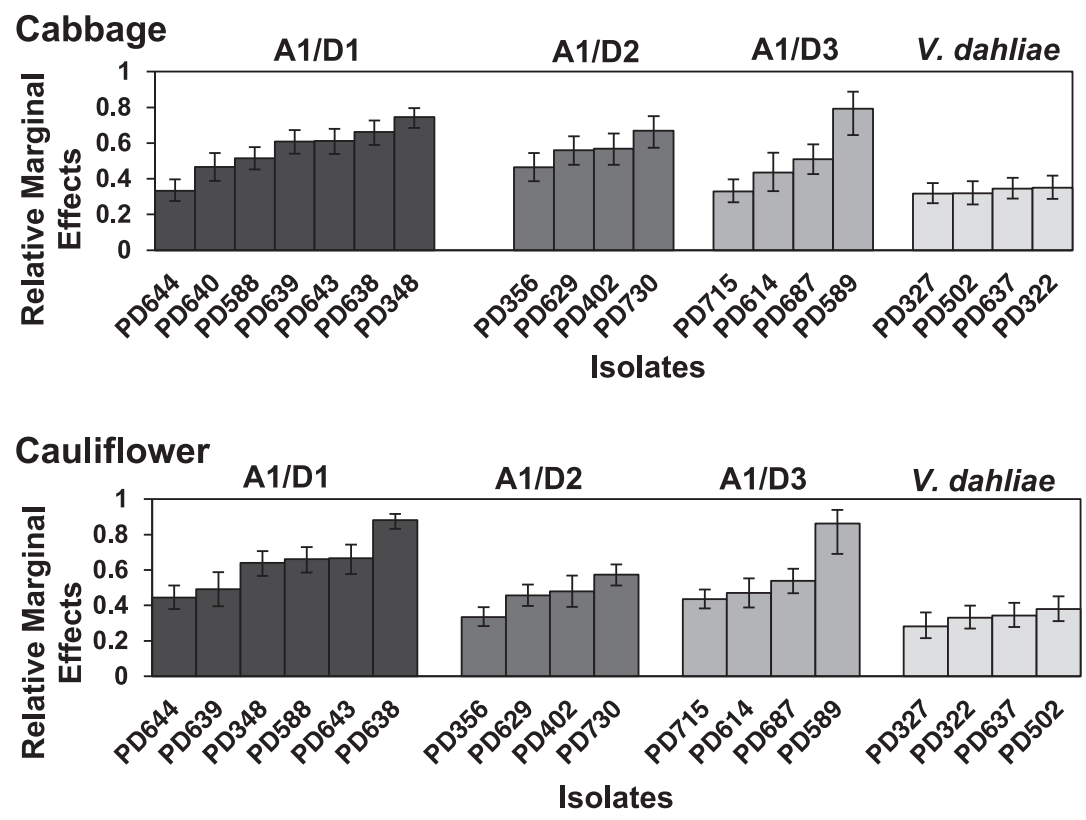

\section{Horseradish}
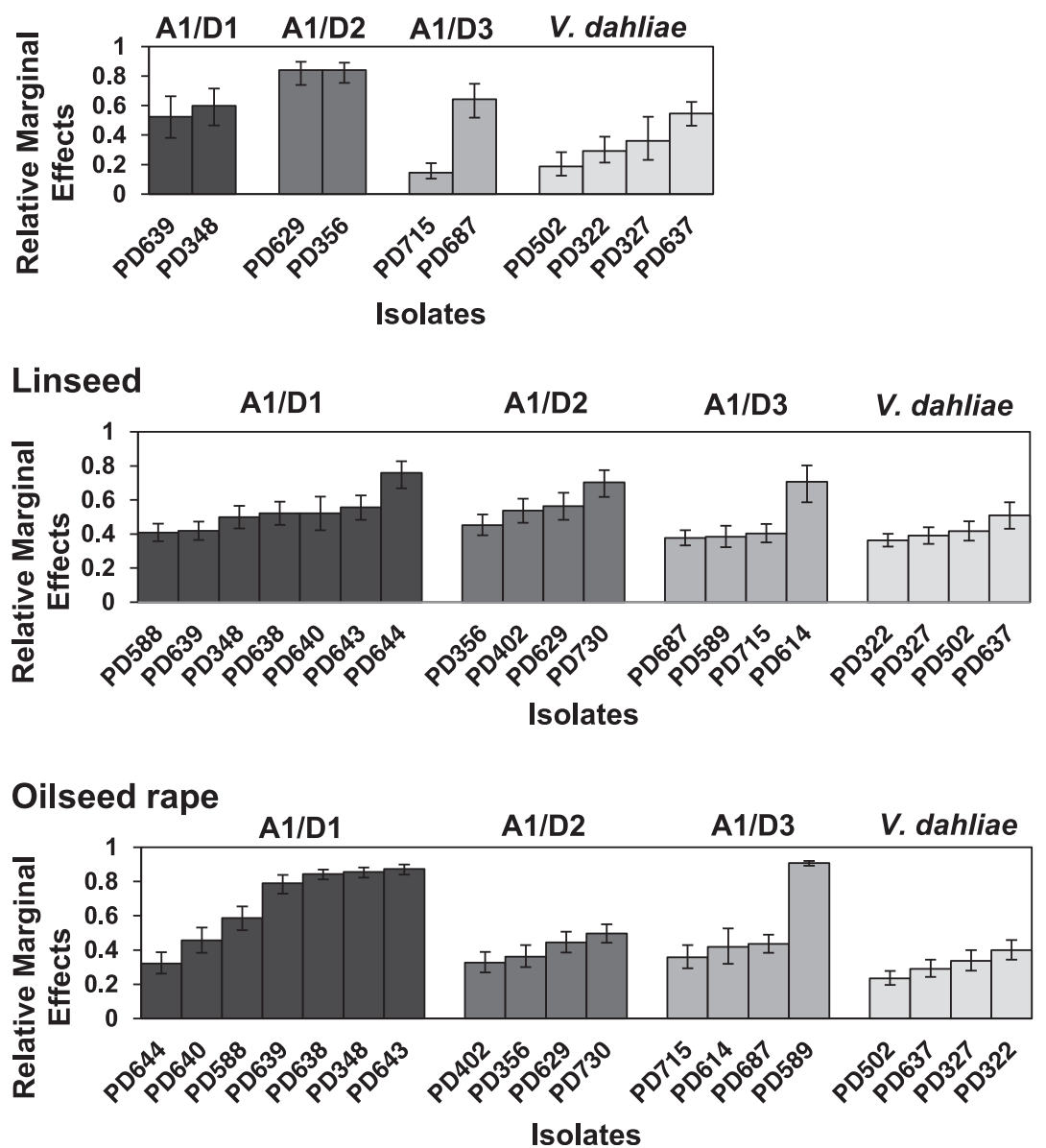

Fig. 6. Estimated relative marginal effects of virulence of individual Verticillium dahliae and V. longisporum isolates on University of Göttingen hosts grouped according to affiliation with V. longisporum lineages A1/D1, A1/D2, and A1/D3 and $V$. dahliae; $95 \%$ confidence intervals are provided. 
Within species and lineages across all hosts combined and on individual hosts, there were virulence differences between isolates within all V. longisporum lineages (Fig. 6). No single isolate was most or least virulent across all individual crops, as illustrated by the significant host-isolate interaction term in Table 4.

Brassicaceae versus non-Brassicaceae hosts. To illustrate susceptibility of Brassicaceae and non-Brassicaceae hosts against
V. dahliae and V. longisporum, we generated a Brassicaceae dataset that comprised the data from cabbage, cauliflower, horseradish, and oilseed rape. The effect of lineage and species was significant in the Brassicaceae dataset (Supplementary Table S5). Across all Brassicaceae hosts combined, $V$. longisporum lineage A1/D1 was the most virulent group and $V$. dahliae was least virulent (Table 8). This was contrasted with the non-Brassicaceae experiment involving

\section{Cabbage}

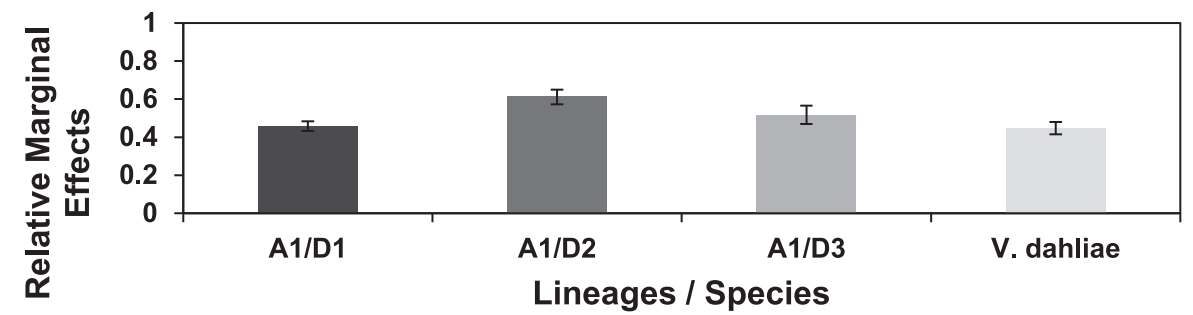

\section{Cauliflower}

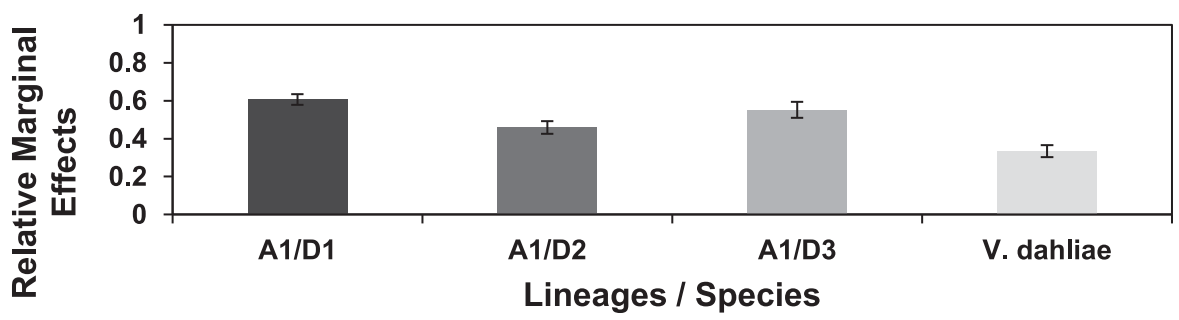

\section{Horseradish}

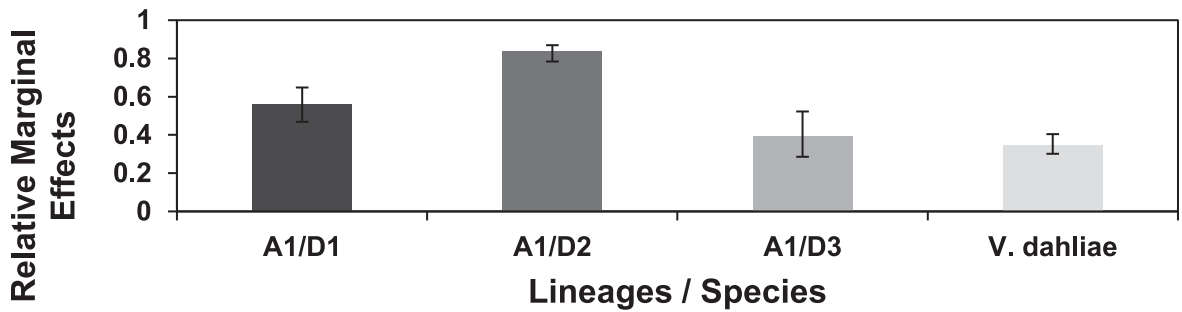

\section{Linseed}

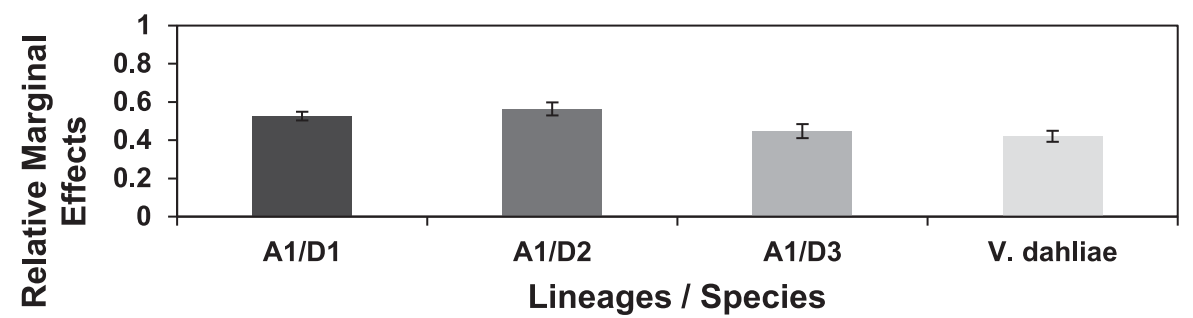

\section{Oilseed rape}

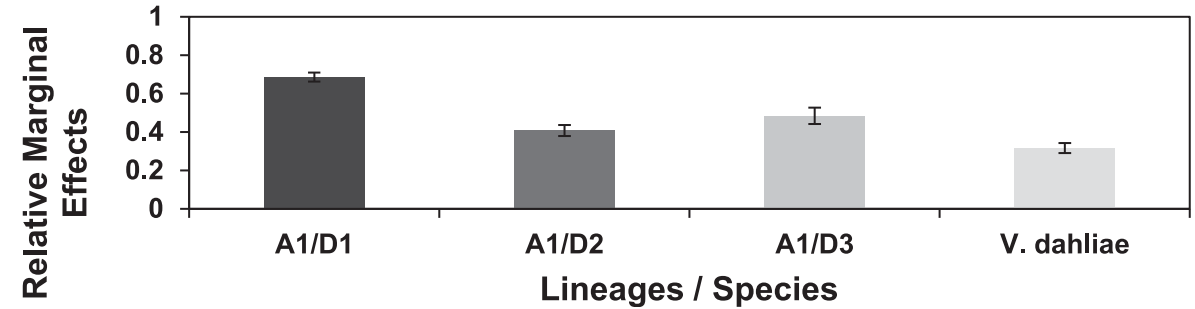

Fig. 7. Estimated relative marginal effects of virulence on individual University of Göttingen hosts of Verticillium dahliae and V. longisporum lineages; $95 \%$ confidence intervals are provided. 
artichoke, cotton, eggplant, lettuce, tomato, and watermelon, where $V$. dahliae overall was the most virulent group, and the three V. longisporum lineages were equally virulent (Fig. 8).

\section{DISCUSSION}

We demonstrated that there are significant differences in virulence and pathogenicity among the $V$. longisporum lineages and between $V$. longisporum and $V$. dahliae. V. longisporum was more virulent than $V$. dahliae on all Brassicaceae hosts tested, including cabbage, cauliflower, horseradish, and oilseed rape, but virulence of $V$. longisporum depended on the host and lineage. $V$. longisporum lineage A1/D1 was the most virulent group across all Brassicaceae crops and, among individual crops, V. longisporum lineage A1/D1 was the most virulent group on oilseed rape and marginally more virulent on cauliflower than $V$. longisporum lineage A1/D3. V. longisporum lineage A1/D2 was the most virulent group on cabbage and horseradish, whereas $V$. longisporum lineage A1/D3 was never the most virulent lineage on any of the hosts tested. However, V. longisporum lineage A1/D3 strain PD589 was among the most virulent isolates on oilseed rape.

Our finding that $V$. longisporum lineage A1/D1 overall is more virulent on cauliflower and oilseed rape than $V$. longisporum lineage A1/D3 agrees with Zeise and von Tiedemann (32,33), whose V. longisporum groups lsp and lsp* correspond to $V$. longisporum lineages A1/D1 and A1/D3, respectively (15). Babadoost et al. (1) showed that $V$. longisporum lineage A1/D2 isolates were virulent on horseradish. Our assays confirmed these results, and also showed that $V$. longisporum lineage A1/D2 was most virulent on horseradish among the $V$. longisporum lineages and $V$. dahliae. It is interesting that all $\mathrm{V}$. longisporum lineage A1/D2 isolates used in our study were originally isolated from horseradish. However, the horseradish isolates were not host specific, because V. longisporum lineage A1/ D2 was also the most virulent group on cabbage.

The fact that $V$. longisporum was more virulent on the Brassicaceae crops than $V$. dahliae was expected, because $V$. longisporum is a pathogen of Brassicaceae, whereas $V$. dahliae generally affects other hosts (9). The only non-Brassicaceae host from which $V$. longisporum was isolated was sugar beet (16). However, in our assays, at least one of the $V$. longisporum lineages was more or equally virulent than $V$. dahliae on eggplant, tomato, lettuce, and watermelon, suggesting that, under field conditions, $V$. longisporum may have a wider potential host range than is currently appreciated.

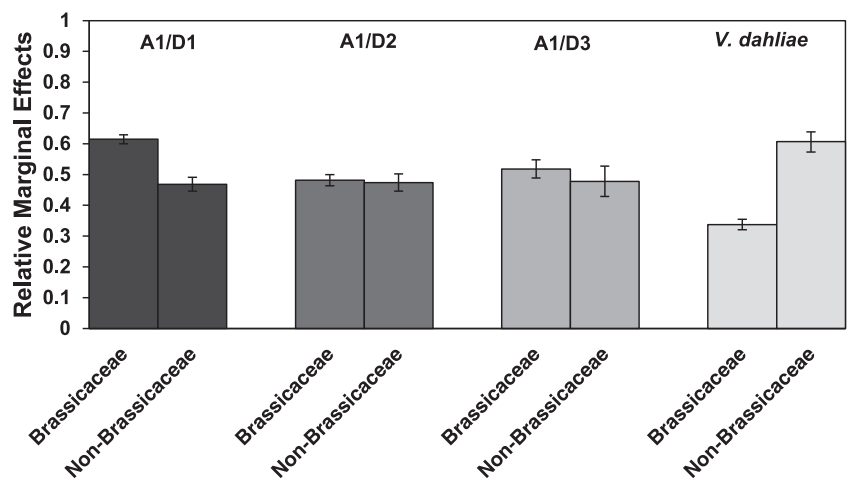

Fig. 8. Comparison of estimated relative marginal effects (RME) of virulence between Brassicaceae and non-Brassicaceae hosts for Verticillium dahliae and $V$. longisporum lineages; 95\% confidence intervals are provided. The Brassicaceae and non-Brassicaceae data were generated in different experiments analyzed separately, so that the confidence intervals cannot be used to compare Brassicaceae and a non-Brassicaceae RME. Noncrucifer RME are from Figure 4 (top). Brassicaceae hosts are cabbage, cauliflower, horseradish and oilseed rape; non-Brassicaceae hosts are artichoke, cotton, eggplant, lettuce, tomato, and watermelon.
Our studies led to the following practical considerations. $V$. longisporum lineage A1/D1 was previously introduced into the Salinas Valley of California, where it caused Verticillium wilt on cauliflower $(21,27)$ but has since disappeared. Our results show that $V$. longisporum lineage A1/D1 is also among the most virulent groups on other crops grown in California, including eggplant and watermelon, which are potential hosts should V. longisporum lineage A1/D1 be reintroduced. Another issue is Verticillium infection of oilseed rape, which is a potentially yield-limiting disease in Europe but is absent from North America (12). The disease is caused by $V$. longisporum lineage A1/D1, which is known from Europe, California, and Japan but has not been documented from Canada or the oilseed-rape-growing regions of the United States (15). However, V. longisporum lineage A1/D2 is known from horseradish in Illinois, which is in relative proximity to some of the major oilseed-rape-growing areas in the United States, including Minnesota, North Dakota, and Oklahoma (http://www.uscanola. $\mathrm{com} /$ ). We were unable to include North American varieties of oilseed rape in our assays but, on the European oilseed rape varieties, $V$. longisporum lineage A1/D2 was the least virulent lineage of $V$. longisporum and, thus, $V$. longisporum lineage A1/D2 may not pose a risk to the North American oilseed-rape-growing regions.

Our results lay the framework for investigations into the genetic bases of the virulence differences between the $V$. longisporum lineages and between $V$. longisporum and $V$. dahliae. These differences may be due to genetic changes associated with the hybridization process, as has been documented in plants (13), and also to the unique genetic contributions made to the hybrid by the individual parental lineages. Brasier $(3,4)$ speculated that previously geographically separated nonpathogens could hybridize to form new pathogens. This appears to be the case for $V$. longisporum, particularly for $V$. longisporum lineage A1/D1, which, overall, was the most virulent lineage of $V$. longisporum in Brassicaceae crops. None of the ancestral species of $V$. longisporum lineage A1/D1, Species A1 and Species D1, have ever been found (15), suggesting that Species A1 and Species D1 are not pathogenic on any of the agricultural crops and are more likely to be associated with nonagricultural hosts, or they are nonpathogenic saprotrophs, similarly to $V$. nubilum $(14,17)$. Very little is known about the natural hosts of Verticillium spp. (16). Such knowledge, particularly pertaining to Species A1 and Species D1, would be crucial to understanding the genetics of the origin of $V$. longisporum lineage A1/D1, one of the most serious oilseed rape pathogens today.

\section{ACKNOWLEDGMENTS}

We thank the following individuals for providing strains used in this research: M. Babadoost (University of Illinois, United States), the late D. Barbara (University of Warwick, United Kingdom), H. Sakai (Department of Agriculture, Gunma Prefecture, Japan), G. Stanosz (University of Wisconsin, United States), M. Typas (University of Athens, Greece), T. Usami (Chiba University, Japan), and I. Happstadius (Lantmännen Lantbruk, Svalöv, Sweden); R. M. Davis (UC Davis) for providing cotton seed; R. M. Bostock (UC Davis) for making his lab space available for this work; K. Godfrey and T. Simpson (UC Davis) for help in the greenhouse; S. Herbert, R. Marchebout, K. Maruthachalam, K. McConnell, D. Short, E. Vorbeck, J. Schaper, D. Tacke, and M. Knobel for excellent assistance in the greenhouse and laboratory; and USDA-NIFA-SCRI grant number 201051181-21069 and the California Leafy Greens Research Board for the funding that made these studies possible.

\section{LITERATURE CITED}

1. Babadoost, M., Chen, W., Bratsch, A. D., and Eastman, C. E. 2004. Verticillium longisporum and Fusarium solani: Two new species in the complex of internal discoloration of horseradish roots. Plant Pathol. 53: 669-676.

2. Bhat, R., and Subbarao, K. V. 1999. Host range specificity in Verticillium dahliae. Phytopathology 89:1218-1225. 
3. Brasier, C. M. 2000. The rise of the hybrid fungi. Nature 405:134-135.

4. Brasier, C. M. 2001. Rapid evolution of introduced plant pathogens via interspecific hybridization. Bioscience 51:123-133.

5. Brunner, E., Domhof, S., and Langer, F. 2002. Nonparametric Analysis of Longitudinal Data in Factorial Experiments. John Wiley \& Sons, New York.

6. Bugbee, W. M., and Sappenfield, W. P. 1968. Varietal reaction of cotton after stem or root inoculation with Fusarium oxysporum f. sp. vasinfectum. Phytopathology 58:212-214.

7. Dixelius, C., Happstadius, I., and Berg, G. 2005. Verticillium wilt on Brassica oilseed crops_-A Swedish perspective. J. Swed. Seed Assoc. 115:36-48.

8. Dunker, S., Keunecke, H., Steinbach, P., and von Tiedemann, A. 2008. Impact of Verticillium longisporum on yield and morphology of winter oilseed rape (Brassica napus) in relation to systemic spread in the plant. J. Phytopathol. 156:698-707.

9. Eynck, C., Koopmann, B., Grunewaldt-Stoecker, G., Karlovsky, P., and von Tiedemann, A. 2007. Differential interactions of Verticillium longisporum and $V$. dahliae with Brassica napus detected with molecular and histological techniques. Eur. J. Plant Pathol. 118:259-274.

10. Eynck, C., Koopmann, B., Karlovsky, P., and von Tiedemann, A. 2009. Internal resistance in winter oilseed rape inhibits systemic spread of the vascular pathogen Verticillium longisporum. Phytopathology 99: 802-811.

11. Fradin, E. F., and Thomma, B. P. H. J. 2006. Physiology and molecular aspects of Verticillium wilt diseases caused by $V$. dahliae and V. alboatrum. Mol. Plant Pathol. 7:71-86.

12. Heale, J. B., and Karapapa, V. K. 1999. The Verticillium threat to Canada's major oilseed crop, Canola. Can. J. Plant Pathol. 21:1-7.

13. Hegarty, M. J., and Hiscock, S. J. 2005. Hybrid speciation in plants: New insights from molecular studies. New Phytol. 165:411-423.

14. Inderbitzin, P., Bostock, R. M., Davis, R. M., Usami, T., Platt, H. W., and Subbarao, K. V. 2011. Phylogenetics and taxonomy of the fungal vascular wilt pathogen Verticillium, with the descriptions of five new species. PLoS One 6:e28341.

15. Inderbitzin, P., Davis, R. M., Bostock, R. M., and Subbarao, K. V. 2011. The ascomycete Verticillium longisporum is a hybrid and a plant pathogen with an expanded host range. PLoS One 6:e18260.

16. Inderbitzin, P., and Subbarao, K. V. 2014. Verticillium systematics and evolution: How confusion impedes Verticillium wilt management and how to resolve it. Phytopathology 104:564-574.

17. Isaac, I. 1953. A further comparative study of pathogenic isolates of Verticillium: V. nubilum Pethybr. and V. tricorpus sp. nov. Trans. Br. Mycol. Soc. 36:180-195.

18. Kabir, Z., Bhat, R. G., and Subbarao, K. V. 2004. Comparison of media for recovery of Verticillium dahliae from soil. Plant Dis. 88:49-55.
19. Keunecke, H. 2009. Einfluss von Kohlfliegenbefall auf die Infektion und Schadwirkung von Verticillium longisporum und Phoma lingam an Raps. Georg-August-University, Göttingen, Germany.

20. Khan, A., Atibalentja, N., and Eastburn, D. M. 2000. Influence of inoculum density of Verticillium dahliae on root discoloration of horseradish. Plant Dis. 84:309-315.

21. Koike, S. T., Subbarao, K. V., Davis, R. M., Gordon, T. R., and Hubbard, J. C. 1994. Verticillium wilt of cauliflower in California. Plant Dis. 78:1116-1121.

22. Paun, O., Fay, M. F., Soltis, D. E., and Chase, M. W. 2007. Genetic and epigenetic alterations after hybridization and genome doubling. Taxon 56:649-656.

23. Pegg, G. F., and Brady, B. L. 2002. Verticillium Wilts. CABI Publishing, Wallingford, Oxon, UK.

24. Shah, D. A., and Madden, L. V. 2004. Nonparametric analysis of ordinal data in designed factorial experiments. Phytopathology 94:33-43.

25. Singh, S., Braus-Stromeyer, S. A., Timpner, C., Valerius, O., von Tiedemann, A., Karlovsky, P., Druebert, C., Polle, A., and Braus, G. H. 2012. The plant host Brassica napus induces in the pathogen Verticillium longisporum the expression of functional catalase peroxidase which is required for the late phase of disease. Mol. Plant-Microbe Interact. 25:569-581.

26. Sorensen, L. H., Schneider, A. T., and Davis, J. R. 1991. Influence of sodium polygalacturonate sources and improved recovery of Verticillium spp. from soil. (Abstr.) Phytopathology 81:1347.

27. Subbarao, K. V., Chassot, A., Gordon, T. R., Hubbard, J. C., Bonello, P., Mullin, R., Okamoto, D., Davis, R. M., and Koike, S. T. 1995. Genetic relationships and cross pathogenicities of Verticillium dahliae isolates from cauliflower and other crops. Phytopathology 85:1105-1112.

28. Tran, V., Braus-Stromeyer, S. A., Timpner, C., and Braus, G. H. 2013. Molecular diagnosis to discriminate pathogen and a pathogen species of the hybrid Verticillium longisporum on the oilseed crop Brassica napus. Appl. Microbiol. Biotechnol. 97:4467-4483.

29. Vallad, G. E., Qin, Q.-M., Grube, R., Hayes, R. J., and Subbarao, K. V. 2006. Characterization of race-specific interactions among isolates of Verticillium dahliae pathogenic on lettuce. Phytopathology 96:1380-1387.

30. Wilhelm, S. 1955. Longevity of the Verticillium wilt fungus in the laboratory and field. Phytopathology 45:180-181.

31. Zeise, K. 1992. Gewächshaustest zur Resistenzprüfung von Winterraps (Brassica napus L. var. oleifera Metzger) gegen den Erreger der Rapswelke Verticillium dahliae Kleb. Nachrichtenbl. Deut. Pflanzenschutzd. 44:125-128.

32. Zeise, K., and von Tiedemann, A. 2002. Host specialization among vegetative compatibility groups of Verticillium dahliae in relation to Verticillium longisporum. J. Phytopathol. 150:112-119.

33. Zeise, K., and von Tiedemann, A. 2002. Application of RAPD-PCR for virulence type analysis within Verticillium dahliae and V. longisporum. J. Phytopathol. 150:557-563. 